\title{
Optimized Conditions for Flavonoid Extraction from Pomelo Peel Byproducts under Enzyme- and Ultrasound-Assisted Extraction Using Response Surface Methodology
}

\author{
Mai Nguyen Tram Anh,, Pham Van Hung $\mathbb{D}^{1,2}$, and Nguyen Thi Lan Phi $\mathbb{C}^{2,3}$ \\ ${ }^{1}$ Department of Food Technology, International University in Ho Chi Minh City, Quarter 6, Linh Trung Ward, Thu Duc District, \\ Ho Chi Minh, Vietnam \\ ${ }^{2}$ Vietnam National University in Ho Chi Minh City, Ho Chi Minh, Vietnam \\ ${ }^{3}$ Department of Food Technology, Ho Chi Minh City University of Technology, 268 Ly Thuong Kiet Street, District 10, \\ Ho Chi Minh, Vietnam \\ Correspondence should be addressed to Nguyen Thi Lan Phi; lanphi@hcmut.edu.vn
}

Received 30 November 2020; Revised 26 December 2020; Accepted 6 January 2021; Published 16 January 2021

Academic Editor: Francesco Genovese

Copyright ( 2021 Mai Nguyen Tram Anh et al. This is an open access article distributed under the Creative Commons Attribution License, which permits unrestricted use, distribution, and reproduction in any medium, provided the original work is properly cited.

\begin{abstract}
Pomelo (Citrus maxima (Burm.) Merrill) peel, which has been considered as a byproduct, is a potential source of flavonoids. In this study, the extraction conditions of total flavonoids from peels of Da Xanh pomelo were optimized using the response surface methodology with the Box-Behnken design. The combination of two novel extraction methods, including enzyme-assisted and ultrasound-assisted extractions, was used for the optimization. The results indicated that the optimal extraction condition was a liquid-to-solid ratio of $142.99 \mathrm{~mL} / \mathrm{g}$, enzyme concentration of $3.45 \%$, and the time of $65.23 \mathrm{~min}$ for incubation and of $69.26 \mathrm{~min}$ for sonication treatment. Total phenolic and total flavonoid contents of the pomelo peel extracts, under optimal condition of the combined method (16.79 mg GAE/g and $10.69 \mathrm{mg} \mathrm{RE} / \mathrm{g}$, respectively), were significantly higher than those of the conventional method (6.58 mg GAE/g and $2.42 \mathrm{mg} \mathrm{RE} / \mathrm{g}$, respectively). The naringin and hesperidin contents of extracts under optimal condition increased by $5.70 \%$ and $1.20 \%$, respectively, compared to the extracts under the conventional method.
\end{abstract}

\section{Introduction}

Pomelo (Citrus maxima (Burm.) Merrill) is classified as one of the major fruits over the world and mainly in tropical and subtropical areas including Vietnam with the largest fruit production. Pomelo contains a wide variety of nutrients and essential bioactive compounds, especially flavonoids. Pomelo flavonoids play an important role in deterrence of life-threatening diseases due to their phenolic profile and antioxidant properties $[1,2]$. In addition, citrus flavonoids have some health-related properties such as anticancer, antiviral, anti-inflammatory, capillary fragility reduction, and human platelet aggregation restriction [3]. Beneficial bioactive compounds are not only present in the juice but also in the residues of citrus juice production, including peels and seeds [1, 2]. As an antioxidant, anticancer, antiviral, and anti-inflammatory agent, flavonoids in pomelo peel contribute to preventing cardiovascular diseases, diabetes, and other diseases [4]. However, pomelo is currently used mainly as fresh fruit or as processed juice and a huge amount of pomelo peels, accounted for $30 \%$ of the fruit weight, are generated as waste or byproduct without considering their potential nutritional values [5].

Traditionally, flavonoids from pomelo peels extraction are mainly based on the extracting ability of different solvents in combination with heat and/or mixing. However, long extraction time, selective solvent requirement, low solvent recovery ability, and thermal decomposition of desired compounds are limitations of the conventional methods [6]. To overcome these limitations, it is necessary to look for novel environmentally friendly methods, which shorten extraction time, reduce solvent consumption, and 
enhance the yield and quality of the extracts. Recently, the enzyme-assisted extraction (EAE) and ultrasound-assisted extraction (UAE) are considered as "green techniques" due to their compliance with the standards of the Environmental Protection Agency, USA. The EAE uses water as solvent instead of organic chemicals for extraction of bioactive compounds and oil and is considered as eco-friendly technology [7]. Moreover, the EAE also enhances the extraction efficiencies of phenolics, flavonoids, anthocyanins, and carotenoids [8]. Likewise, the UAE has been used as a clean, green, and economic technique, alternative to conventional techniques, for extracting various bioactive compounds from fruits and vegetables $[9,10]$. Popularly, flavonoids have been extracted using the one-variable-at-atime optimization method to obtain higher yield of extraction [11]. However, the interactive effects among the variables used in the process are not included and the complete effects of the parameters on the process are not clearly determined [12]. To overcome this limitation, the response surface methodology (RSM) was used to optimize conditions of extraction method for getting the highest bioactive compounds. The optimization was designed using the Box-Behnken design, a spherical and revolving design for several chemical and physical processes with excellent outcomes [13]. Nishad et al. [14] reported that the bioactive compounds from Citrus sinensis cv. Malta peel were extracted using the EAE with the optimized condition of $0.84 \%$ for enzyme concentration, $30.94 \mathrm{ml} / \mathrm{g}$ for solvent-solid ratio, and $4.87 \mathrm{~h}$ for extraction time, whereas the optimized condition for extraction using the UAE was $70.89 \%$ for amplitude, $40 \mathrm{ml} / \mathrm{g}$ for solvent-solid ratio, and 35 min for extraction time. The EAE was also found to be more effective with twofold higher yield of phenolics than UAE [14]. In this study, the operational parameters of the combination of enzyme- and ultrasound-assisted extraction for obtaining the highest flavonoid from pomelo peels were optimized using the RSM with the Box-Behnken design. Moreover, the chemical composition and functional properties of extracts under the optimal extraction condition, using enzyme-assisted and ultrasound-assisted extraction method, were also obtained and compared with those of traditional extraction method.

\section{Materials and Methods}

2.1. Materials. Da Xanh pomelo, grown in Dong Nai province of Vietnam, was used. The voucher specimens of the plant (no. HCMUT201) was detected by Dr. Lan Phi Nguyen, a professor at the University of Technology, VNUHCM. The fruits chosen for the experiments were nearly similar in the uniformity of shape and size and ripeness, and they did not contain any contamination including insects and smelly and rotten parts.

Gallic acid, naringin, hesperidin, and 2, 2-diphenyl-1picrylhydrazyl (DPPH) were all purchased from Sigma Aldrich Co. The HPLC-grade acetonitrile and methanol were obtained from Merck Co. Enzyme Pectinex Ultra SP-L (CAS: 9032-75-1) from Aspergillus aculeatus of Novozymes Co. was used in this study.
2.2. Sample Preparation. Pomelo fruits were carefully washed with water before peeling to obtain the pomelo green peel layer only. Pomelo peels were then cut into small pieces and dried at $60^{\circ} \mathrm{C}$ for $24 \mathrm{~h}$ using a forced draft oven (UNE 700, Memmert, Germany). After that, the dried peels were grinded into powder and passed through a 100-mesh sieve and then stored in a freezer (DW-65GL538, MRC Lab, Israel) at $-20^{\circ} \mathrm{C}$ prior to the experiments.

\subsection{Enzyme-Assisted and Ultrasound-Assisted Extraction} Method. Pomelo peel powder (1 g, dry basis) was mixed with a certain amount of deionized water with different ratios (50, 150 , or $250 \mathrm{~mL}$ ) and then added with an amount of pectinase $(0.5,2.5$, or $4.5 \%, \mathrm{v} / \mathrm{m})$. The mixture was shaken well and incubated in shaking incubator at different incubation times $(40,60$, or $80 \mathrm{~min})$. After that, the mixture was placed in an ultrasonic bath (WUC-A10H, $40 \mathrm{kHz}$, Daihan, Korea) for certain time $(30,60$, or $90 \mathrm{~min})$ at a constant temperature $30^{\circ} \mathrm{C}$. Then the mixture was placed in a water bath at $90^{\circ} \mathrm{C}$ for $5 \mathrm{~min}$ to deactivate enzyme. The extracts were obtained by centrifugation at $6,000 \mathrm{rpm}$ for $15 \mathrm{~min}$ at $4^{\circ} \mathrm{C}$. Finally, pomelo peel extracts were stored in the refrigerator before analysis.

2.4. Experimental Design. A four-variable, three-level Box-Behnken design (BBD) was employed in this study with the independent variables of liquid-to-solid ratio $\left(\mathrm{mL} / \mathrm{g}, X_{1}\right)$, enzyme concentration $\left(\mathrm{v} / \mathrm{m}, X_{2}\right)$, incubation time ( $\left.\mathrm{min}, X_{3}\right)$, and ultrasonic time $\left(\mathrm{min}, X_{4}\right)$ at the three levels $(-1,0$, and +1 ) of each (Table 1). The response of the design was yield $(Y)$ of extraction. Twenty-nine experiments were carried out with five center points used to evaluate the pure error.

The correlation between the yield and the independent variables is expressed in a second-order polynomial regression model as follows:

$$
Y=a_{0}+\sum_{i=1}^{4} a_{i} X_{i}+\sum_{i=1}^{4} a_{i i} X_{i}^{2}+\sum_{i=1}^{3} \sum_{j=i+1}^{4} a_{i j} X_{i} X_{j}
$$

where $Y$ is the response variable (TFC); $a_{0}$ is a constant coefficient; $a_{i}, a_{i i}$, and $a_{i j}$ are the regression coefficients of variables for intercept quadratic, linear, and interaction terms, respectively; and $X_{i}$ and $X_{j}$ represent the level of the independent variables.

ANOVA was carried out to determine the regression coefficients and significance of the selected model. Further $3 \mathrm{D}$ surface plots were obtained to show the correlation between the process variables and responses.

2.5. Conventional Extraction Method. Pomelo peel was extracted using a conventional method as previously reported by Soong et al. [15] with slight modification. The dried peel $(1 \mathrm{~g})$ was accurately weighed and refluxed with a total volume of $44 \mathrm{~mL}$ of ethanol, placed in a water bath at $31^{\circ} \mathrm{C}$ for $35 \mathrm{~min}$. After incubation, the mixture was centrifuged at $3,000 \times \mathrm{g}$ for $15 \mathrm{~min}$ and then the supernatant was 
TABLE 1: Experimental values of the independent variables used in the Box-Behnken design (BBD).

\begin{tabular}{lccc}
\hline Factor & -1 & 0 & +1 \\
\hline Liquid-to-solid ratio, $X_{1}(\mathrm{~mL} / \mathrm{g})$ & 50 & 150 & 250 \\
Enzyme concentration, $X_{2}(\mathrm{v} / \mathrm{m})$ & 0.5 & 2.5 & 4.5 \\
Incubation time, $X_{3}(\mathrm{~min})$ & 40 & 60 & 80 \\
Ultrasonic time, $X_{4}(\mathrm{~min})$ & 30 & 60 & 90 \\
\hline
\end{tabular}

collected and kept. The residue was continued with the above steps for more 2 times. After collection, the solution was evaporated and then made up with methanol to get $20 \mathrm{~mL}$ of final extract.

2.6. Measurement of Total Phenolic Content. The total phenolic content (TPC) of extracts was measured using the Folin-Ciocalteu assay based on method previously reported by Jeong et al. [16]. The extract $(0.5 \mathrm{~mL})$ was mixed with the Folin-Ciocalteu reagent $(0.5 \mathrm{~mL})$ and the saturated sodium carbonate $(1.0 \mathrm{~mL})$ and then added with distilled water to the final volume of $10 \mathrm{~mL}$. The mixture was thoroughly mixed and incubated at ambient temperature for $45 \mathrm{~min}$ without light. After centrifugation at $3,000 \times \mathrm{g}$ for $5 \mathrm{~min}$, the supernatant was collected and measured for absorbance at $725 \mathrm{~nm}$ using a UV-Vis spectrophotometer (Genesys 10S UV-Vis, USA). Gallic acid solutions with different concentration of $20,40,60,80$, and $100 \mu \mathrm{g} / \mathrm{mL}$ were used to form the standard curve and the results were expressed in milligrams gallic acid equivalent per gram of sample (mg GAE/ g).

2.7. Measurement of Total Flavonoids Content (TFC). The TFC was measured using colorimetric method according to the method previously reported by Hung et al. [17] with slight modification. The extract $(0.5 \mathrm{~mL}), 95 \%$ ethanol $(1 \mathrm{~mL}), 1 \mathrm{M}$ potassium acetate $(0.1 \mathrm{~mL})$, and $10 \%$ aluminium chloride solution $(0.1 \mathrm{~mL})$ were mixed well and then added to distilled water to final volume of $5 \mathrm{~mL}$. The mixture was kept at ambient temperature for $30 \mathrm{~min}$ without light and then measured for absorbance at $415 \mathrm{~nm}$ using a UV-Vis spectrophotometer (Genesys 10S UV-Vis, USA). Rutin solutions with different concentrations of 20,40,60, 80, and $100 \mu \mathrm{g} / \mathrm{mL}$ were used to form standard calibration and the results were expressed in milligrams rutin equivalent (RE) per gram of sample (mg RE/g).

2.8. HPLC Analysis. The key flavonoid compounds of pomelo peel's extract including naringin and hesperidin were analyzed according to the method of Ribeiro and Ribeiro [18]. The standard compounds purchased from Sigma-Aldrich Co. (Singapore) were naringin ( $\geq 90 \%$, from citrus fruit, code: N1376-25G) and hesperidin ( $\geq 80 \%$, code: H5254-25G). The analysis was carried out using an HPLC system (Dionex Ultimate 3000 HPLC System, USA) with a C18 column $(150 \mathrm{~mm} \times 4.6 \mathrm{~mm}, 5 \mu \mathrm{m}$ particle size; Wakosil-II 5C18 HG, Japan). Acetonitrile (solvent A) and water (solvent B) were used as the mobile phase with gradient elution as follows: $23 \% \mathrm{~A}$ in $8 \mathrm{~min}$; $23-65 \% \mathrm{~A}$ in
$7 \mathrm{~min}$; $65-70 \% \mathrm{~A}$ in $5 \mathrm{~min} ; 70-23 \% \mathrm{~A}$ in $1 \mathrm{~min}$; and $23 \% \mathrm{~A}$ in $1 \mathrm{~min}$. The flow rate of mobile phase was $1 \mathrm{~mL} / \mathrm{min}$, the injection volume was $10 \mu \mathrm{L}$, and the peaks were detected at $280 \mathrm{~nm}$.

2.9. DPPH Scavenging Analysis. The antioxidant capacity of pomelo peel extracts was measured using the DPPH scavenging method according to the method of Hung et al. [17]. The extract $(0.1 \mathrm{~mL})$ and the DPPH solution $(0.075 \mathrm{mM})$ $(3.9 \mathrm{~mL})$ were mixed well and then kept at ambient temperature without light for $30 \mathrm{~min}(t=30)$. After incubation, the solution was immediately measured for absorbance at $515 \mathrm{~nm}$ using a UV-Vis spectrophotometer (Genesys 10S UV-Vis, USA). A mixture of water $(0.1 \mathrm{~mL})$ and the DPPH solution $(3.9 \mathrm{~mL})$ was used as a blank and the absorbance was determined at the same wavelength immediately after mixing $(t=0)$. The scavenging of DPPH was calculated as follows:

$$
\% \text { DPPH scavenging }=\left[\operatorname{Abs}(t=0)-\frac{\operatorname{Abs}(t=30)}{\operatorname{Abs}(t=0)}\right] \times 100 \text {. }
$$

2.10. Statistical Analysis. Analysis of variance (ANOVA) was used to analyze the data obtained from triplicate experiments to determine differences $(p<0.05)$ using the Statistical Package for the Social Sciences (SPSS software version 16; SPSS Inc., USA).

\section{Results and Discussion}

3.1. The Model Fitting and Statistical Analysis. Four independent variables, including the liquid-to-solid ratio, enzyme concentration, incubation time, and ultrasonic time, were used as process parameters in the optimized experiments according to the Box-Behnken design ( $4^{3}$ factorial). The experimental design and corresponding response data of flavonoids extracted from the Da Xanh pomelo peel is shown in Table 2. Based on the obtained results, the total flavonoid content from extracts ranged from 8.02 to $11.09 \mathrm{mg} / \mathrm{g}$ sample $(\mathrm{db})$. The equation in terms of coded factors was used to make predictions about the response for given levels of each factor. By applying multiple regression analysis on the experimental data, the response variable and test variables were related by the following second-order polynomial equation:

$$
\begin{aligned}
Y= & +10.80-0.28 X_{1}+0.2272 X_{2}+0.1587 X_{3}+0.1950 X_{4} \\
& +0.2872 X_{1} X_{2}-0.2322 X_{1} X_{3}+0.0145 X_{1} X_{4}+0.6987 X_{2} X_{3} \\
& +0.2157 X_{2} X_{4}-0.3844 X_{3} X_{4}-1.50 X_{1}^{2}-0.4801 X_{2}^{2} \\
& -0.7439 X_{3}^{2}-0.3177 X_{4}^{2}
\end{aligned}
$$

where $X_{1}, X_{2}, X_{3}$, and $X_{4}$ were the coded values of the liquid to solid ratio, enzyme concentration, incubation time, and ultrasonic time, respectively. 
TABLE 2: Box-Behnken design and observed responses.

\begin{tabular}{|c|c|c|c|c|c|}
\hline \multirow[b]{2}{*}{ Run } & \multicolumn{4}{|c|}{ Independent variable } & \multirow[b]{2}{*}{ Response (TFC, mg RE/g db) } \\
\hline & $\begin{array}{c}X_{1} \\
\text { Ratio }(\mathrm{mL} / \mathrm{g})\end{array}$ & $\begin{array}{c}X_{2} \\
\text { Enzyme concentration }(\%, \mathrm{v} / \mathrm{m})\end{array}$ & $\begin{array}{c}X_{3} \\
\text { Incubation time (min) }\end{array}$ & $\begin{array}{c}X_{4} \\
\text { Ultrasonic time }(\min )\end{array}$ & \\
\hline 1 & 150 & 2.5 & 40 & 90 & 10.32 \\
\hline 2 & 150 & 4.5 & 40 & 60 & 9.01 \\
\hline 3 & 50 & 2.5 & 60 & 30 & 8.99 \\
\hline 4 & 150 & 4.5 & 60 & 30 & 9.83 \\
\hline 5 & 50 & 2.5 & 40 & 60 & 8.54 \\
\hline 6 & 150 & 4.5 & 60 & 90 & 10.49 \\
\hline 7 & 250 & 2.5 & 60 & 90 & 8.90 \\
\hline 8 & 150 & 0.5 & 80 & 60 & 8.64 \\
\hline 9 & 150 & 2.5 & 40 & 30 & 8.92 \\
\hline 10 & 150 & 0.5 & 60 & 90 & 9.82 \\
\hline 11 & 250 & 4.5 & 60 & 60 & 9.19 \\
\hline 12 & 150 & 2.5 & 60 & 60 & 10.73 \\
\hline 13 & 150 & 2.5 & 80 & 30 & 9.98 \\
\hline 14 & 250 & 2.5 & 40 & 60 & 8.16 \\
\hline 15 & 250 & 2.5 & 80 & 60 & 8.19 \\
\hline 16 & 50 & 2.5 & 80 & 60 & 9.50 \\
\hline 17 & 150 & 2.5 & 80 & 90 & 9.85 \\
\hline 18 & 50 & 2.5 & 60 & 90 & 9.26 \\
\hline 19 & 150 & 0.5 & 40 & 60 & 9.87 \\
\hline 20 & 150 & 2.5 & 60 & 60 & 10.62 \\
\hline 21 & 150 & 4.5 & 80 & 60 & 10.57 \\
\hline 22 & 150 & 0.5 & 60 & 30 & 10.02 \\
\hline 23 & 150 & 2.5 & 60 & 60 & 10.90 \\
\hline 24 & 50 & 0.5 & 60 & 60 & 9.09 \\
\hline 25 & 150 & 2.5 & 60 & 60 & 10.69 \\
\hline 26 & 50 & 4.5 & 60 & 60 & 9.11 \\
\hline 27 & 150 & 2.5 & 60 & 60 & 11.09 \\
\hline 28 & 250 & 2.5 & 60 & 30 & 8.58 \\
\hline 29 & 250 & 0.5 & 60 & 60 & 8.02 \\
\hline
\end{tabular}

The adequacy of model was checked using ANOVA, and the model fit summary is displayed in Table 3. The highestorder polynomial was selected where the additional terms were significant, and the model was not aliased. It was evident that quadratic model was significant at the level of $p<0.05$, whereas the other models were insignificant $(p>0.05)$.

In order to determine whether the quadratic model was significant, the statistical significance of regression equation was checked by the F-test and ANOVA for response surface quadratic polynomial model (Table 4 ). The F-value of the model was 41.78, implying that the model was significant. There was only a $0.01 \%$ chance that the $F$-value could occur due to noise. In addition, the $p$ value was used as a tool to check the significance of each coefficient, which also indicated the interaction strength of each parameter. The $p$ values of less than 0.05 indicated that the model terms were significant and the values of greater than 0.05 indicated that the model terms were insignificant. In this study, the statistical analysis with high significance level $(p<0.0001)$ showing the goodness of fit of the model in case of flavonoids extraction. The determination coefficient $\left(R^{2}=0.9766\right)$ was close to 1 , which indicated the satisfactory correlation between actual values and predicted ones [12]. The adjusted $R^{2}$ value was 0.9532 , which meant most variance $(>95.32 \%)$ of the total flavonoid content could be predicted by the model, while only $5 \%$ variation could not be explained by the model.

The lack-of-fit F-value of 1.05 implied that the lack of fit was not significant relative to the pure error (Table 4). There was a $52.60 \%$ chance that the lack-of-fit $F$-value could occur due to noise, thereby confirming the validity of the model. The value of coefficient of variation (C.V.) was $2.02 \%$, which suggests that the model is reproducible [19]. Adequate precision compared the range of predicted values at the design points to the average prediction error. A ratio greater than 4 was desirable and indicated adequate model discrimination. In this study, the value of 20.048 indicated an adequate signal. This model could be used to navigate the design space. The results indicated that the model could work well for the prediction of flavonoids extract from Da Xanh pomelo using enzyme-assisted and ultrasound-assisted extraction method.

The regression coefficients and the corresponding $p$ values were also presented in Table 4 . From the $p$ value of each model term, it could be concluded that all the independent variables studied $\left(X_{1}, X_{2}, X_{3}\right.$, and $\left.X_{4}\right)$ and four quadratic terms $\left(X_{1}^{2}, X_{2}^{2}, X_{3}^{2}\right.$, and $\left.X_{4}^{2}\right)$ significantly affected the total flavonoid yield extracted from Da Xanh pomelo peel. Moreover, the analysis showed the interactions between two arbitrary parameters were significant except for the interaction between liquid-to-solid ratio and sonication time $\left(X_{1} X_{4}\right)$. 
TABLE 3: Summary of fitting model.

\begin{tabular}{lcccc}
\hline Source & Sequential $p$ value & Lack-of-fit $p$ value & Adjusted $R^{2}$ & Predicted $R^{2}$ \\
\hline Linear & 0.5882 & 0.0027 & -0.0420 & -0.2209 \\
2FI & 0.7322 & 0.0020 & -0.1602 & -0.6634 \\
Quadratic & $<\mathbf{0 . 0 0 0 1}$ & $\mathbf{0 . 5 2 6 0}$ & $\mathbf{0 . 9 5 3 2}$ & $\mathbf{0 . 8 9 2 4}$ \\
Cubic & 0.3542 & 0.6185 & 0.9617 & 0.7379 \\
\hline
\end{tabular}

TABLE 4: ANOVA for response surface quadratic model analysis of the experimental results ${ }^{1}$.

\begin{tabular}{|c|c|c|c|c|c|}
\hline Source & $\begin{array}{l}\text { Sum of } \\
\text { squares }\end{array}$ & Df & $\begin{array}{l}\text { Mean } \\
\text { square }\end{array}$ & $\begin{array}{c}F- \\
\text { value }\end{array}$ & $p$ value \\
\hline Model & 21.72 & 14 & 1.55 & 41.78 & $<0.0001$ \\
\hline$X_{1}$ & 0.9974 & 1 & 0.9974 & 26.86 & 0.0001 \\
\hline$X_{2}$ & 0.6193 & 1 & 0.6193 & 16.68 & 0.0011 \\
\hline$X_{3}$ & 0.3024 & 1 & 0.3024 & 8.14 & 0.0128 \\
\hline$X_{4}$ & 0.4562 & 1 & 0.4562 & 12.29 & 0.0035 \\
\hline$X_{1} X_{2}$ & 0.3299 & 1 & 0.3299 & 8.88 & 0.0099 \\
\hline$X_{1} X_{3}$ & 0.2157 & 1 & 0.2157 & 5.81 & 0.0303 \\
\hline$X_{1} X_{4}$ & 0.0008 & 1 & 0.0008 & 0.0225 & 0.8829 \\
\hline$X_{2} X_{3}$ & 1.95 & 1 & 1.95 & 52.59 & $<0.0001$ \\
\hline$X_{2} X_{4}$ & 0.1861 & 1 & 0.1861 & 5.01 & 0.0420 \\
\hline$X_{3} X_{4}$ & 0.5911 & 1 & 0.5911 & 15.92 & 0.0013 \\
\hline$X_{1}^{2}$ & 14.51 & 1 & 14.51 & 390.72 & $<0.0001$ \\
\hline$X_{2}^{2}$ & 1.50 & 1 & 1.50 & 40.27 & $<0.0001$ \\
\hline$X_{3}^{2}$ & 3.59 & 1 & 3.59 & 96.67 & $<0.0001$ \\
\hline$X_{4}^{2}$ & 0.6546 & 1 & 0.6546 & 17.63 & 0.0009 \\
\hline Residual & 0.5198 & 14 & 0.0371 & & \\
\hline Lack of fit & 0.3765 & 10 & 0.0376 & 1.05 & 0.5260 \\
\hline Pure error & 0.1433 & 4 & 0.0358 & & \\
\hline Cor total & 22.24 & 28 & & & \\
\hline$R^{2}$ & 0.9766 & & & & \\
\hline Adjusted $R^{2}$ & 0.9532 & & & & \\
\hline Predicted $R^{2}$ & 0.8924 & & & & \\
\hline $\begin{array}{l}\text { Adeq } \\
\text { precision }\end{array}$ & 20.0476 & & & & \\
\hline C.V. \% & 2.02 & & & & \\
\hline
\end{tabular}

$X_{1}$ : liquid-to-solid ratio $(\mathrm{mL} / \mathrm{g}) ; X_{2}$ : enzyme concentration $(\%, \mathrm{v} / \mathrm{m}) ; X_{3}$ : incubation time $(\mathrm{min})$; and $\mathrm{X}_{4}$ : ultrasonic time $(\mathrm{min})$.

3.2. Analysis of Response Surface. In order to evaluate the interaction effects of the independent factors on the response, the best way is to generate surface response plots of the model, which were done by varying two variables within the experimental range under investigation and keeping the other two variables at their zero level. Three-dimensional response surface plots and two-dimensional contour plots were effectively used to express the interaction, since the former one illustrated the sensitiveness of response value toward the change of variable and the latter one described significant coefficients between different variables [12].

Figures 1(a), 1(d), and 1(e) and Figures 2(a), 2(d), and 2 (e) show the combined effects of enzyme concentration and liquid-to-solid ratio, enzyme concentration and incubation time, and enzyme concentration and sonication time on the extraction yield of flavonoids, respectively. In all situations, the yield of flavonoids increased with increasing enzyme concentration from 0.5 to $3.5 \%(\mathrm{v} / \mathrm{m})$, while enzyme concentration of more than $3.5 \%$ had negative effect on the extraction yield, indicating that enzyme concentration had remarkable effect on the yield of flavonoids. In fact, there were several significant parameters that impacted on the effectiveness of enzyme in the degradation and disruption of cell wall structure and release of the target bioactive compounds, such as enzyme type and concentration, type of extraction solvent, solid-to-liquid ratio, enzyme/substrate ratio, $\mathrm{pH}$, extraction temperature, and time [11]. The increase in the enzyme/substrate ratio improved the catalytic reaction rate; however, over the optimal range of enzyme concentration, the substrate was used up and the enzyme's active sites were no longer saturated, and the reaction decreased. Moreover, increasing enzyme concentration also increased the enzyme usage and resultant cost at the same time.

Figures 1(a), 1(b), and 1(c) and Figures 2(a), 2(b), and 2(c) show the combined effects of the liquid-to-solid ratio and each of other factors on the extraction yield of flavonoids. In all interactions with other factors, the liquid-tosolid ratio had significant effects and there was a clear optimal value of liquid-to-solid ratio that peaked around the range $130-160 \mathrm{~mL} / \mathrm{g}$. When the amount of the enzyme was kept constant and the substrate concentration was then gradually increased, the reaction velocity increased until it reached a maximum value. After this point, the increase in substrate concentration did not increase the velocity.

The combined effects of the incubation time and each of other factors on the extraction yield of flavonoids are shown in Figures 1(b), 1(d), and 1(f) and Figures 2(b), 2(d), and $2(\mathrm{f})$. It was obvious that longer incubation time resulted in higher yield and the extraction yield of flavonoids increased to a maximum value with increasing incubation time from 40 to $70 \mathrm{~min}$ and thereafter decreased. As mentioned above, temperature was an important factor in the enzymatic reaction which usually increase the reaction rate and simultaneously mass transfer rate; thus, in this study, the temperature of incubation was set at the optimal value for enzyme work of $50^{\circ} \mathrm{C}$. Increasing incubation time led to the increasing of reaction until it reached the maximum value. After that, the formation of the contemporary enzymesubstrate complex became the inhibitor which caused the decreasing of reaction.

The combined effects of ultrasonic time and each of other factors on the flavonoid yield are displayed in Figures 1(c), 1(e), and 1(f) and Figures 2(c), 2(e), and 2(f). As observed from these figures, the ultrasonic time had less significant impact on flavonoids yield than other factors. The extraction yield of flavonoids increased when the ultrasonic time increased from 30 to $70 \mathrm{~min}$.

As a result, the highest extraction yield of flavonoids extracted from Da Xanh pomelo peel was obtained using the enzyme-assisted and ultrasound-assisted extraction method 


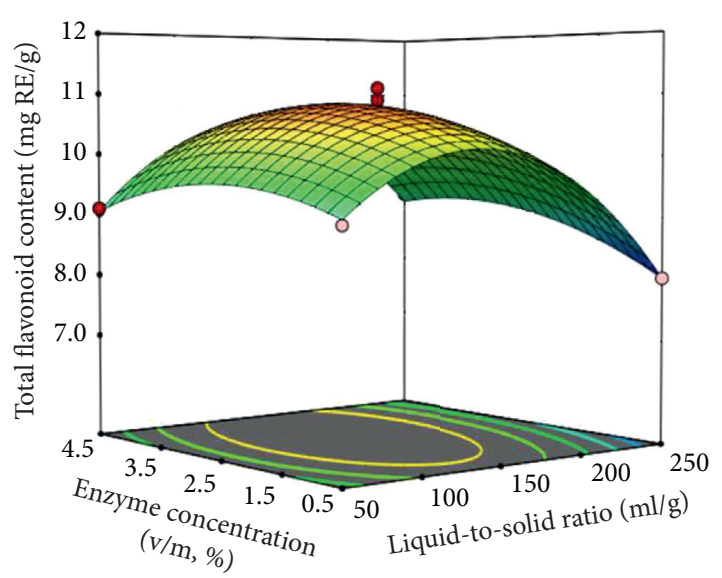

(a)

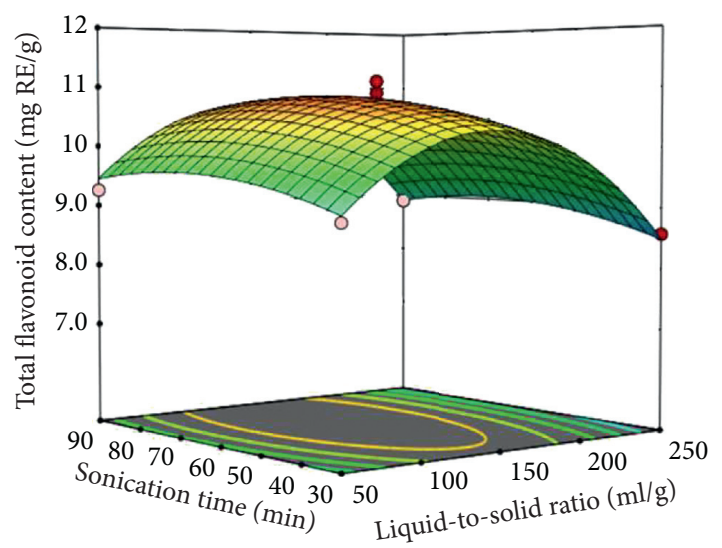

(c)

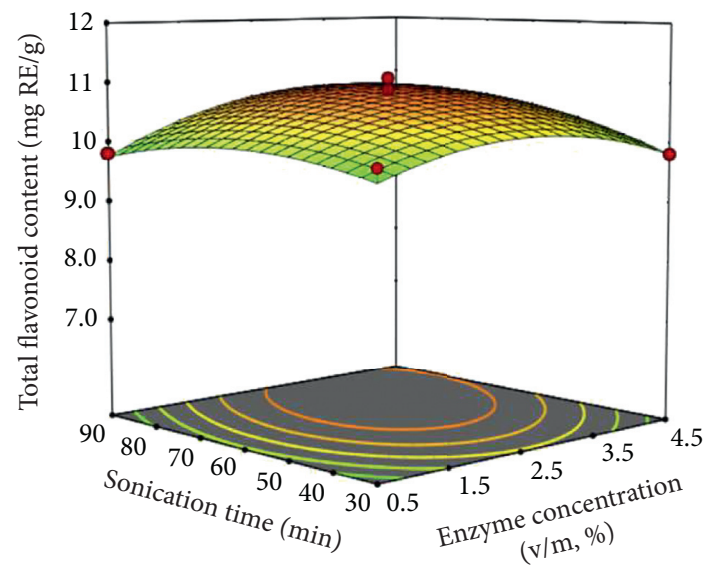

(e)

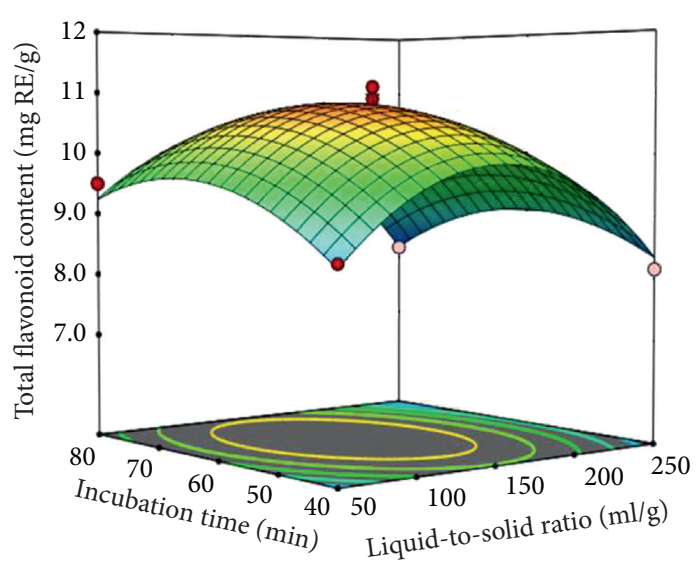

(b)

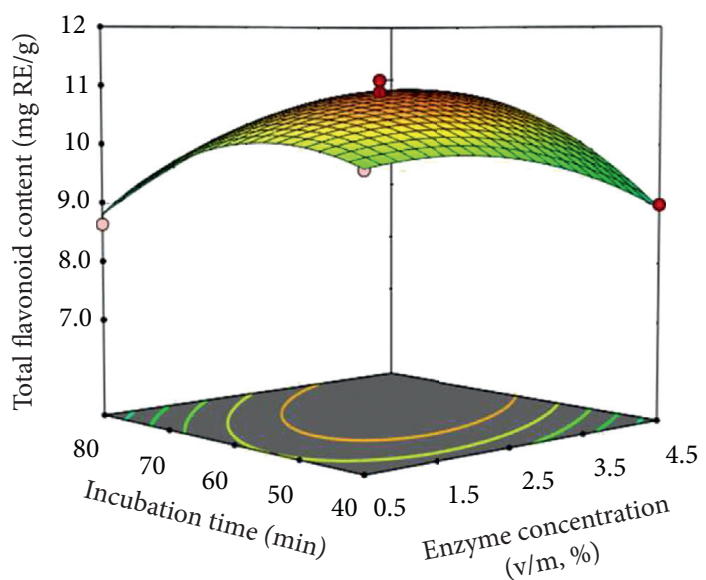

(d)

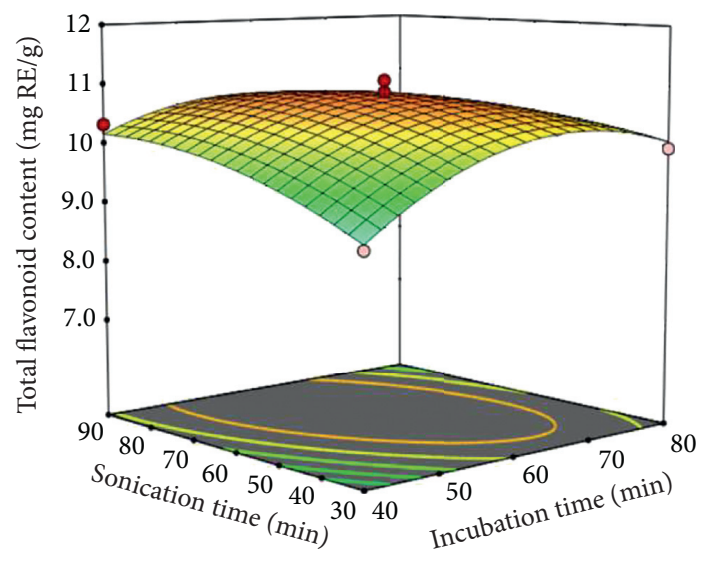

(f)

FIGURE 1: Response surface plots (3D) showing the effects of different extraction parameters on extraction yield of flavonoids from Da Xanh pomelo peel (a) at varying liquid-to-solid ratio and enzyme concentration, (b) at varying liquid-to-solid ratio and incubation time, (c) at varying liquid-to-solid ratio and ultrasonic time, (d) at varying enzyme concentration and incubation time, (e) at varying enzyme concentration and ultrasonic time, and (f) at varying incubation time and ultrasonic time.

with the ratio of liquid to solid of $142.99 \mathrm{~mL} / \mathrm{g}$, enzyme concentration of $3.45 \%(\mathrm{v} / \mathrm{m})$, incubation time of $65.23 \mathrm{~min}$, and ultrasound time of 69.26 min (Figure 3 ). The suitability of the model equation for predicting the optimal response values was confirmed by doing the experiment at the selected optimal condition. The experimental extraction yield of flavonoids was $10.69 \pm 0.07 \mathrm{mg} \mathrm{RE} / \mathrm{g}(n=3)$, which was not significantly different from the predicted value of $10.92 \mathrm{mg} \mathrm{RE} / \mathrm{g}$ (Table 5). 


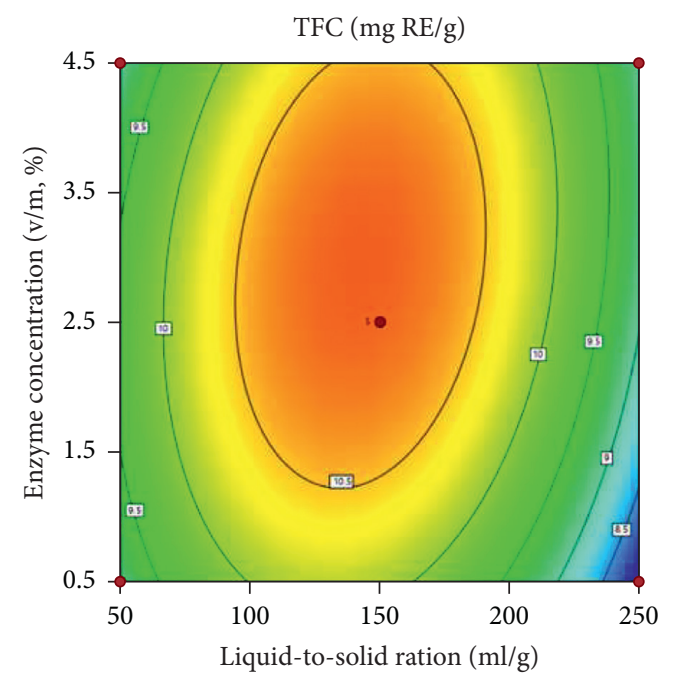

(a)

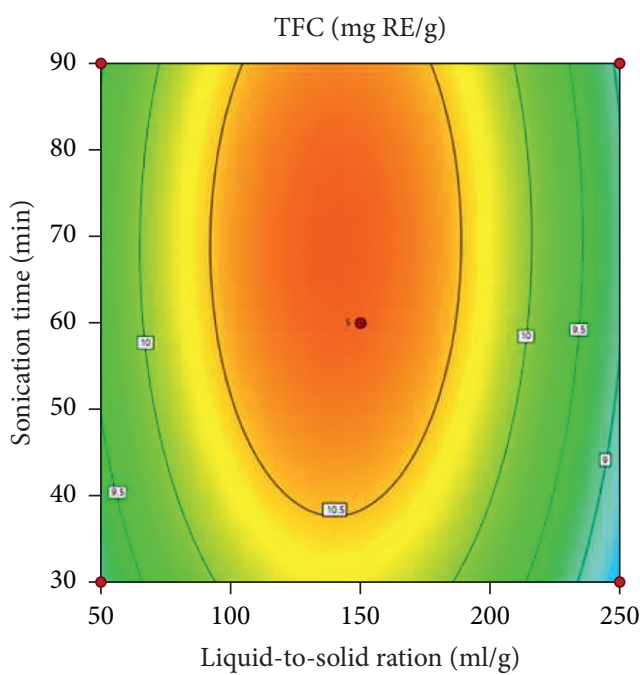

(c)



(e)

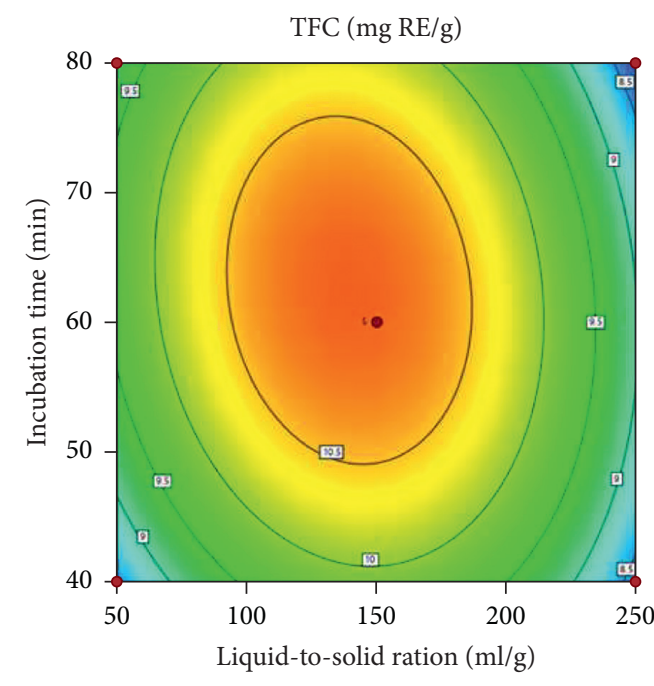

(b)

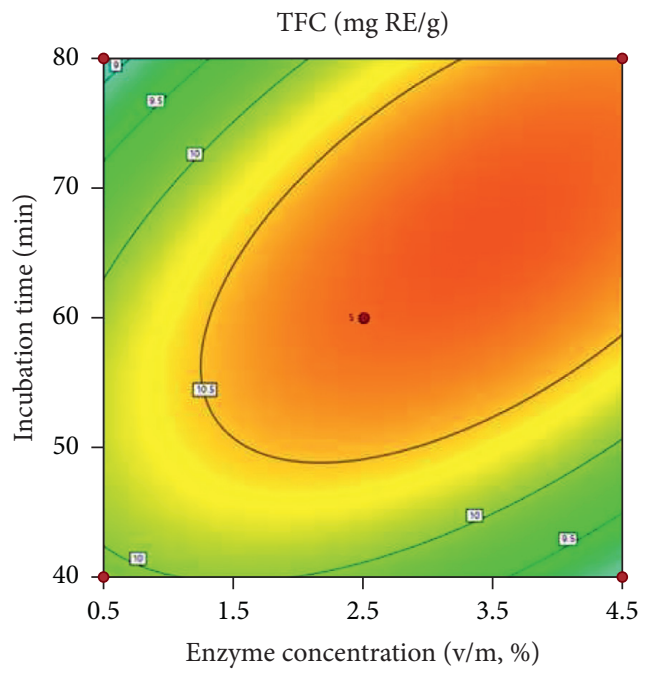

(d)

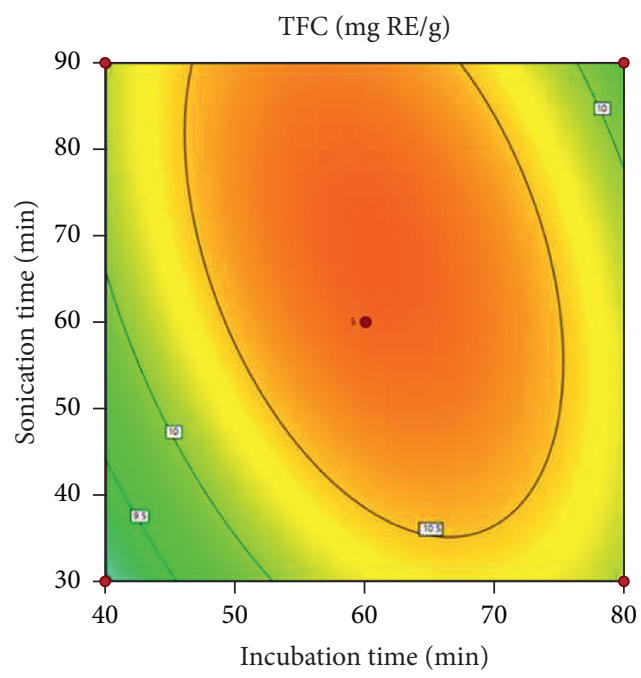

(f)

FIGURE 2: Contour plots (2D) showing the effect of different extraction parameters showing the effects of different extraction parameters on extraction yield of flavonoids from Da Xanh pomelo peel (a) at varying liquid to solid ratio and enzyme concentration, (b) at varying liquid to solid ratio and incubation time, (c) at varying liquid to solid ratio and ultrasonic time, (d) at varying enzyme concentration and incubation time, (e) at varying enzyme concentration and ultrasonic time, and (f) at varying incubation time and ultrasonic time. 




Liquid-to-solid ratio $=142.992$

(a)



Incubation time $=65.2296$

(c)

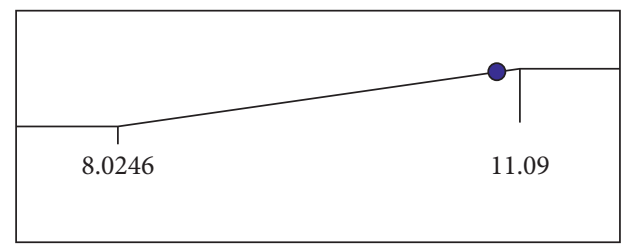

Total flavonoid content $=10.9192$

(e)

FIGURE 3: Desirability ramp for optimized conditions for extraction process.
Desirability $=0.944$ Solution 1 out of 1 (b)

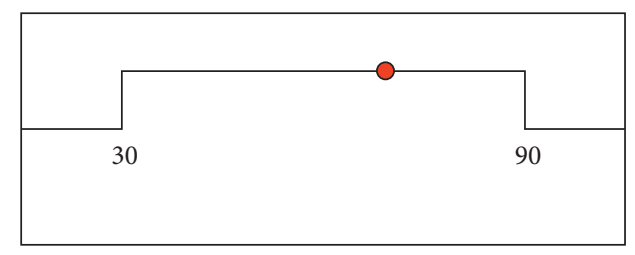

Sonication time $=69.2563$

(d)
Comparison of chemical composition and functional properties of pomelo peel extracts obtained from different extraction conditions was carried out.

The flavonoids of $\mathrm{Da}$ Xanh pomelo peel were extracted under the optimal conditions of two extraction methods, the enzyme-assisted and ultrasound-assisted extraction method and the organic solvent conventional method, to know their efficiencies. The TPC and TFC of pomelo peel extracts under the optimal conditions investigated in this study (DX-W) were $16.79 \pm 0.43 \mathrm{mg} \mathrm{GAE} / \mathrm{g}$ peel $(\mathrm{db})$ and $10.69 \pm 0.07 \mathrm{mg}$ $\mathrm{RE} / \mathrm{g}$ peel $(\mathrm{db}$ ), respectively (Table 6). Meanwhile, the TPC and TFC of the extract obtained by the conventional method with ethanol as solvent (DX-E) was $6.58 \pm 0.22 \mathrm{mg} \mathrm{GAE} / \mathrm{g}$ peel $(\mathrm{db})$ and $2.42 \pm 0.03 \mathrm{mg} \mathrm{RE} / \mathrm{g}$ peel $(\mathrm{db})$, respectively. It is obvious that the extraction by combination of enzymeassisted and ultrasound-assisted extraction method significantly improved the TPC and TFC of the extract from Da Xanh pomelo peel compared to the conventional method. Enzyme was used to catalyze the hydrolysis of components resistant to mass transfer such as cell wall or material matrix. The addition of pectinase during the extraction enhanced the recovery of target compounds by degrading and disrupting the pectic substances which played role as structural polysaccharide in the middle lamella and primary cell wall. The presence of macerating side-activities in the Pectinex Ultra SP-L preparation such as cellulases and hemicellulases resulted in the completed breakdown of the polysaccharide structure and improved the extraction yield [11]. Moreover, under the effects of acoustic cavitation which was phenomenon of creation, expansion, and implosive collapse of microbubbles in ultrasound-irradiated liquids created by sonication, the solute quickly diffused from the matrix to the extracting liquid with enhanced mass transfer across membranes [10]. Application of ultrasound combining with enzymes was reported to enhance extraction yields of target compounds. Low-frequency ultrasound enhanced reaction rates by facilitating an increase in collisions between enzyme and substrate. Wu et al. [20] found that the higher recovery of polysaccharides was obtained when applying ultrasound to enzyme pretreated samples or simultaneous enzyme and ultrasound extraction compared to conventional extraction, EAE or UAE alone. Similarly, Tchabo et al. [21] observed a significant increase in yields of phytochemicals from mulberry must for ultrasound-assisted enzymatic extraction compared to UAE alone, enzyme alone, or a conventional extraction technique.

The DPPH free radical scavenging of the pomelo peel extracts from different extraction methods is also displayed in Table 6. The DPPH radical scavenging activities of the DX-W were significantly higher than the DX-E extracts $(25.45 \pm 0.03 \%$ and $22.70 \pm 0.04 \%$, respectively). In fact, the high content of flavonoids shows a positive correlation with their antioxidant capacity [22]. Thus, the combination of enzyme and ultrasound had positive effects on the antioxidant activities of pomelo peel extracts from Da Xanh pomelo compared to the conventional extraction method.

Flavonoid profile of the Da Xanh pomelo peel extracts investigated using HPLC equipment is presented in Table 6. 
TABle 5: Predicted and experimental values of the responses at optimal conditions ${ }^{1,2}$.

\begin{tabular}{lccccc}
\hline & & \multicolumn{2}{c}{ Independent variables } & & \multirow{2}{*}{ TFC (mg RE/g) } \\
& Ratio $(\mathrm{mL} / \mathrm{g})$ & Enzyme conc. $(\%, \mathrm{v} / \mathrm{m})$ & Incubation time $(\mathrm{min})$ & Ultrasonic time $(\mathrm{min})$ & 69.26 \\
Theoretical optimal condition & 142.99 & 3.45 & 65.23 & $6.92^{\mathrm{a}}$ \\
Experimental condition & 143 & 3.45 & 65 & 69 & $10.69^{\mathrm{a}}$ \\
\hline
\end{tabular}

${ }^{1}$ TFC: total flavonoid content. ${ }^{2}$ Values (mean \pm standard deviation) followed by the different superscript letter are significantly different $(p<0.05)$.

TABLE 6: Bioactivity properties and flavonoid composition of extracts from different extraction methods ${ }^{1,2}$.

\begin{tabular}{lccccc}
\hline \multirow{2}{*}{ Sample } & \multicolumn{3}{c}{ Bioactivity properties } & \multicolumn{2}{c}{ Flavonoid composition } \\
& TFC $(\mathrm{mg} \mathrm{RE} / \mathrm{g} \mathrm{db})$ & TPC $(\mathrm{mg} \mathrm{GAE} / \mathrm{g} \mathrm{db})$ & Antioxidant activity $(\%)$ & Naringin $(\mathrm{mg} / \mathrm{g} \mathrm{db})$ & Hesperidin $(\mathrm{mg} / \mathrm{g} \mathrm{db})$ \\
\hline DX-W & $10.69 \pm 0.07^{\mathrm{a}}$ & $16.79 \pm 0.43^{\mathrm{a}}$ & $25.45 \pm 0.03^{\mathrm{a}}$ & $6.94 \pm 0.13^{\mathrm{a}}$ & $1.26 \pm 0.05^{\mathrm{a}}$ \\
DX-E & $2.42 \pm 0.03^{\mathrm{b}}$ & $6.58 \pm 0.22^{\mathrm{b}}$ & $22.70 \pm 0.04^{\mathrm{b}}$ & $1.24 \pm 0.06^{\mathrm{b}}$ & $0.06 \pm 0.03^{\mathrm{b}}$ \\
\hline
\end{tabular}

${ }^{1}$ TFC: total flavonoid content; TPC: total phenolics content; DX-W: pomelo peel extract under the optimal conditions of the enzyme-assisted and ultrasoundassisted extraction; DX-E: pomelo peel extract under the optimal conditions of the ethanol conventional extraction. ${ }^{2}$ Values (mean \pm standard deviation) followed by the different superscript letter are significantly different $(p<0.05)$.

Naringin and hesperidin contents of extracts, using the enzyme-assisted and ultrasound-assisted extraction method, were $6.94 \pm 0.13 \mathrm{mg} / \mathrm{g}$ and $1.26 \pm 0.05 \mathrm{mg} / \mathrm{g}$, respectively, significantly higher than those of the extracts using the conventional method $(1.24 \pm 0.06 \mathrm{mg} / \mathrm{g}$ and $0.06 \pm 0.03 \mathrm{mg} /$ $\mathrm{g}$, respectively). The naringin, narirutin, hesperidin, and kaempferol were found in the citrus flavonoid extracts, in which the naringin accounted for $99.8 \%$ and $96.0 \%$ of the total flavanone glycosides in immature and mature pomelo fruits, respectively $[23,24]$. Thus, the results of this study are consistent with the findings of the previous studies.

\section{Conclusion}

In this study, the conditions of the enzyme-assisted and ultrasound-assisted extraction method, for extracting the flavonoids from Da Xanh pomelo peel, were optimized using a fourvariable, three-level experiment Box-Behnken design based on response surface methodology. Under the optimal conditions, the highest total flavonoid concentration was obtained, and the model was significant ( $F$-value of 41.78 and $p$ value of less than $0.001 \%)$. In comparison with the conventional method using ethanol as solvent extraction, the enzyme-assisted and ultrasound-assisted extraction method enhanced extraction yield, TPC, TFC, and antioxidant activities of the extracts. The naringin and hesperidin contents of extracts under the optimal conditions increased by $5.68 \%$ and $1.18 \%$, respectively, compared to the conventional extraction method. The findings gained from this study should be useful for further exploitation and application of sustainable resources.

\section{Data Availability}

The data are available from the corresponding author upon reasonable request.

\section{Disclosure}

The authors hereby declare that the work presented in this article is original and that any liability for claims relating to the content of this article will be borne by them.

\section{Conflicts of Interest}

The authors declare that they have no conflicts of interest regarding the publication of this paper.

\section{Acknowledgments}

This research was funded by Vietnam National University in Ho Chi Minh City (VNU-HCM) under Grant no. B2019-2004.

\section{References}

[1] M. A. Anagnostopoulou, P. Kefalas, V. P. Papageorgiou, A. N. Assimopoulou, and D. Boskou, "Radical scavenging activity of various extracts and fractions of sweet orange peel (Citrus sinensis)," Food Chemistry, vol. 94, no. 1, pp. 19-25, 2006.

[2] R. Guimarães, L. Barros, J. C. M. Barreira, M. J. Sousa, A. M. Carvalho, and I. C. F. R. Ferreira, "Targeting excessive free radicals with peels and juices of citrus fruits: grapefruit, lemon, lime and orange," Food and Chemical Toxicology, vol. 48, no. 1, pp. 99-106, 2010.

[3] S. Rafiq, R. Kaul, S. A. Sofi, N. Bashir, F. Nazir, and G. Ahmad Nayik, "Citrus peel as a source of functional ingredient: a review," Journal of the Saudi Society of Agricultural Sciences, vol. 17, no. 4, pp. 351-358, 2018.

[4] L. Yi, S. Ma, and D. Ren, "Phytochemistry and bioactivity of Citrus flavonoids: a focus on antioxidant, anti-inflammatory, anticancer and cardiovascular protection activities," Phytochemistry Reviews, vol. 16, no. 3, pp. 479-511, 2017.

[5] Z. Zarina and S. Tan, "Determination of flavonoids in Citrus grandis (Pomelo) peels and their inhibition activity on lipid peroxidation in fish tissue," International Food Research Journal, vol. 20, no. 1, pp. 313-317, 2013.

[6] L. Wen, Z. Zhang, D.-W. Sun, S. P. Sivagnanam, and B. K. Tiwari, "Combination of emerging technologies for the extraction of bioactive compounds," Critical Reviews in Food Science and Nutrition, vol. 60, no. 11, pp. 1826-1841, 2020.

[7] M. Puri, D. Sharma, and C. J. Barrow, "Enzyme-assisted extraction of bioactives from plants," Trends in Biotechnology, vol. 30, no. 1, pp. 37-44, 2012.

[8] D.-P. Xu, Y. Li, X. Meng et al., "Natural antioxidants in foods and medicinal plants: extraction, assessment and resources," 
International Journal of Molecular Sciences, vol. 18, no. 1, p. 96, 2017.

[9] F. Chemat, N. Rombaut, A.-G. Sicaire, A. Meullemiestre, A.-S. Fabiano-Tixier, and M. Abert-Vian, "Ultrasound assisted extraction of food and natural products. Mechanisms, techniques, combinations, protocols and applications. A review," Ultrasonics Sonochemistry, vol. 34, pp. 540-560, 2017.

[10] B. K. Tiwari, "Ultrasound: a clean, green extraction technology," TrAC Trends in Analytical Chemistry, vol. 71, pp. 100-109, 2015.

[11] P. V. Hung, N. H. Y. Nhi, L. Y. Ting, and N. T. L. Phi, "Chemical composition and biological activities of extracts from pomelo peel by-products under enzyme and ultrasoundassisted extractions," Journal of Chemistry, vol. 2020, pp. 1-7, Article ID 1043251, 2020.

[12] Z.-L. Sheng, P.-F. Wan, C.-L. Dong, and Y.-H. Li, "Optimization of total flavonoids content extracted from Flos Populi using response surface methodology," Industrial Crops and Products, vol. 43, pp. 778-786, 2013.

[13] S. L. C. Ferreira, R. E. Bruns, H. S. Ferreira et al., "BoxBehnken design: an alternative for the optimization of analytical methods," Analytica Chimica Acta, vol. 597, no. 2, pp. 179-186, 2007.

[14] J. Nishad, S. Saha, and C. Kaur, "Enzyme-and ultrasoundassisted extractions of polyphenols from Citrus sinensis (cv. Malta) peel: a comparative study," Journal of Food Processing and Preservation, vol. 43, no. 8, Article ID e14046, 2019.

[15] Y.-Y. Soong and P. J. Barlow, "Antioxidant activity and phenolic content of selected fruit seeds," Food Chemistry, vol. 88, no. 3, pp. 411-417, 2004.

[16] S.-M. Jeong, S.-Y. Kim, D.-R. Kim et al., "Effect of heat treatment on the antioxidant activity of extracts from citrus peels," Journal of Agricultural and Food Chemistry, vol. 52, no. 11, pp. 3389-3393, 2004.

[17] P. V. Hung and N. Morita, "Distribution of phenolic compounds in the graded flours milled from whole buckwheat grains and their antioxidant capacities," Food Chemistry, vol. 109 , no. 2 , pp. 325-331, 2008.

[18] I. A. Ribeiro and M. H. L. Ribeiro, "Naringin and naringenin determination and control in grapefruit juice by a validated HPLC method," Food Control, vol. 19, no. 4, pp. 432-438, 2008.

[19] G. Zhang, L. He, and M. Hu, "Optimized ultrasonic-assisted extraction of flavonoids from Prunella vulgaris L. and evaluation of antioxidant activities in vitro," Innovative Food Science \& Emerging Technologies, vol. 12, no. 1, pp. 18-25, 2011.

[20] H. Wu, J. Zhu, W. Diao, and C. Wang, "Ultrasound-assisted enzymatic extraction and antioxidant activity of polysaccharides from pumpkin (Cucurbita moschata)," Carbohydrate Polymers, vol. 113, pp. 314-324, 2014.

[21] W. Tchabo, Y. Ma, F. N. Engmann, and H. Zhang, "Ultrasound-assisted enzymatic extraction (UAEE) of phytochemical compounds from mulberry (Morus nigra) must and optimization study using response surface methodology," Industrial Crops and Products, vol. 63, pp. 214-225, 2015.

[22] M. Islam, M. Hoque, S. Monalisa, and K. Monalisa, "Chemical composition, antioxidant capacities and storage stability of Citrus macroptera and Garcinia pedunculata fruits," Emirates Journal of Food and Agriculture, vol. 27, no. 3, pp. 275-282, 2015.

[23] K. Mäkynen, S. Jitsaardkul, P. Tachasamran et al., "Cultivar variations in antioxidant and antihyperlipidemic properties of pomelo pulp (Citrus grandis [L.] Osbeck) in Thailand," Food Chemistry, vol. 139, no. 1-4, pp. 735-743, 2013.

[24] A. Ortuno, D. Garcia-Puig, M. D. Fuster et al., "Flavanone and nootkatone levels in different varieties of grapefruit and pummelo," Journal of Agricultural and Food Chemistry, vol. 43, no. 1, pp. 1-5, 1995. 